University of Nebraska - Lincoln

DigitalCommons@University of Nebraska - Lincoln

Faculty Publications from the Harold W. Manter Laboratory of Parasitology

6-1980

\title{
Biology and Pathogenesis of the Coccidium Eimeria funduli Infecting Killifishes
}

\author{
Mobashir A. Solangi \\ Gulf Coast Research Laboratory \\ Robin M. Overstreet \\ Gulf Coast Research Laboratory, robin.overstreet@usm.edu
}

Follow this and additional works at: https://digitalcommons.unl.edu/parasitologyfacpubs

Part of the Parasitology Commons

Solangi, Mobashir A. and Overstreet, Robin M., "Biology and Pathogenesis of the Coccidium Eimeria funduli Infecting Killifishes" (1980). Faculty Publications from the Harold W. Manter Laboratory of Parasitology. 460.

https://digitalcommons.unl.edu/parasitologyfacpubs/460

This Article is brought to you for free and open access by the Parasitology, Harold W. Manter Laboratory of at DigitalCommons@University of Nebraska - Lincoln. It has been accepted for inclusion in Faculty Publications from the Harold W. Manter Laboratory of Parasitology by an authorized administrator of DigitalCommons@University of Nebraska - Lincoln. 


\title{
BIOLOGY AND PATHOGENESIS OF THE COCCIDIUM EIMERIA FUNDULI INFECTING KILLIFISHES
}

\author{
Mobashir A. Solangi and Robin M. Overstreet
}

Gulf Coast Research Laboratory, Ocean Springs, Mississippi 39564

ABSTRACT: Epizootics of Eimeria funduli involved estuarine killifishes (Fundulus grandis, F. pulvereus, $F$. similis, and F. heteroclitus) in Mississippi, Alabama, and Virginia. All of more than 500 specimens examined of $F$. grandis from Mississippi during 1977 through 1979 had infections, regardless of age, sex, or season collected. Oocysts occurred primarily in the liver and pancreas, replacing up to $85 \%$ of both those organs. Infrequent sites of infection were fatty tissue of the body cavity, ovary, intestine, and caudal peduncle. Living fish did not discharge oocysts. Eimeria funduli is the first known eimerian to require a second host. To complete the life cycle, an infective stage in the grass shrimp Palaemonetes pugio had to be eaten. In 6-mo-old killifish reared in the laboratory at $24 \mathrm{C}$, young schizonts were first observed in hepatic and pancreatic cells 5 days postfeeding, followed by first generation merozoites by day 10, differentiation of sexual stages during days 15 to 20, fertilization between days 19 and 26 , sporoblasts from days 25 to 30 , and sporozoites about day 60 . Unique sporopodia developed on sporocysts by day 35 when still unsporulated. Temperatures of 7 to $10 \mathrm{C}$ irreversibly halted schizogony. Both schizogony and sporogony progressed slower as age of host increased. When infective shrimp in doses ranging from 1 to $10 \%$ of a fish's body weight were eaten, the level of intensity of resulting infections did not differ significantly. Pathogenesis followed a specific sequence, with the host response apparently unable to contend with extensive infections as seen typically in nature and in our experiments. Premunition was indicated. When administered Monensin ${ }^{\circledR}$ orally, infected fish exhibited a reduction in oocysts by 50 to $70 \%$ within 20 days as compared with untreated fish. Furthermore, infected killifish maintained exclusively on a diet of TetraMin ${ }^{\circledR}$ for 3 mo completely lost their infections.

Eimeria funduli Duszynski, Solangi, and Overstreet 1979 is an unusual, pathogenic coccidium. Because this hepatic parasite has a stage incorporating a second host and other, apparently unique features, it probably deserves separate generic recognition. We have not yet described characteristics of the stage in the shrimp. Thus, we have refrained from creating a new genus.

During the past few years, infections of $E$. funduli in Mississippi have reached panzootic proportions in the Gulf killifish, Fundulus grandis Baird and Girard. It is suspected that these infections have a detrimental effect on the host population. The killifish serves as a primary forage fish for mammals, birds, and fishes in salt marsh habitats. Fishermen along the northern Gulf of Mexico use the Gulf killifish extensively as bait. The fish supports a growing bait industry (Tatum et al., in press; McIlwain, 1977), and, because of its ease to culture, it can be propagated commercially (Tatum et al., in press). Consequently, E. funduli has considerable influence on the economic potential of the Gulf killifish.

This study reports the life cycle and distribution of the parasite, hepatic alterations in infected fishes, and chemical control of the disease agent.

Received for publication 19 December 1979.

\section{MATERIALS AND METHODS}

Parasite-free $F$. grandis used in this study were spawned by stripping gravid male and female killifish collected from Halstead Bayou in Ocean Springs, Mississippi. Pond-reared, coccidia-free adults were obtained from the Claude Peteet Mariculture Center, Gulf Shores, Alabama. We routinely maintained groups of 15 fish in 75.7-liter glass aquaria with 15 ppt salt (Instant Ocean ${ }^{\circledR}$ ) at approximately $24 \mathrm{C}$. Water, aerated by a corner filter, was exchanged at the rate of 5 to $10 \%$ every $3 \mathrm{wk}$ or when necessary as determined by harmful levels of ammonia, nitrate, nitrite, or dissolved oxygen concentration. We fed killifish daily with a varied diet including Ralston Purina trout chow, frozen fish (sea trouts and Atlantic croaker), and TetraMin ${ }^{\circledR}$.

Naturally infected fish and grass shrimp (Palaemonetes pugio Holthuis) were caught with minnow traps, seines, and dip nets and maintained as indicated above. We separated sporulated oocysts from liver by grinding infected tissue in a Waring Blendor; the homogenate was then passed through 40-, 60-, and 80-mesh brass screens, and the filtrate centrifuged for $5 \mathrm{~min}$ at $2,000 \mathrm{rpm}$ to concentrate oocysts. We further concentrated oocysts occasionally by sugar flotation (Duszynski et al., 1979). Oocysts were stored in $2.5 \%(\mathrm{w} / \mathrm{v})$ potassium dichromate solution at $24 \mathrm{C}$. We examined tissues routinely using squash preparations.

To determine the route of infection, we used six groups each containing 15 fish. Two groups served as controls and the others were fed concentrated sporulated oocysts, naturally infected liver with sporulated oocysts, chopped grass shrimp collected from enzootic areas, or similar grass shrimp fed infected liver 1 to $2 \mathrm{hr}$ earlier. We fed fish daily or every other day throughout the experiment. All 
tests were repeated three times, except those dealing with grass shrimp which were repeated nine times using five fish each time. Additionally, three uninfected pond-reared fish were fed grass shrimp taken directly from enzootic (Mississippi) areas and another three fish were fed uninfected grass shrimp (Alabama ponds) that had been fed oocysts at 2 and $24 \mathrm{hr}$ prior to the experiment.

To study the life cycle and pathogenesis of the coccidium, thirty 6-mo-old fish and thirty 1-yr-old fish were fed naturally infected grass shrimp two times during 1 day. Liver, pancreas, intestine, spleen, kidney, heart, brain, and gonad from two fish of each age group were prepared for histological study at days $5,10,13,15,18,20,23,25,28,30$, 35 , and 40 postfeeding. Additional fish were killed to examine fresh squash-preparations of various tissues at some of these intervals, as well as at days 50,60 , and 70 .

To determine the effect of low temperature on infections, 20 laboratory-reared fish were acclimated at about $24 \mathrm{C}$ and fed naturally infected shrimp for 5 days. Then, at day 5,10 fish were transferred to an aquarium maintained continuously at 7 to 10 C. At day 19, five of the cooled fish were transferred back to $24 \mathrm{C}$, two were sacrificed, and three left in the cold water. Tissues were sectioned at days 19 and 30 . This experiment was repeated once.

To determine the relationship between dose of shrimp eaten and relative intensity of infection, a single test was conducted using groups of 10 fish that were fed 1,5 , or $10 \%$ of their body weight in shrimp over a 1-day period. Individual weight of a fish averaged $2.5 \mathrm{~g}$ and of a shrimp $22 \mathrm{mg}$. A large number of shrimp were diced and pooled. Intensity of oocysts in fish livers was estimated 30 days after the feeding.

An experiment also was conducted to assess the potential of treating infections with the coccidiostat Monensin ${ }^{\circledR}$. Ten naturally infected fish were fed diced fish flesh containing the drug $(0.5 \mathrm{~g}$ crystalline Monensin, lot 329-AC2: 15-g fish fed every 3 days for 20 days). Ten others were injected intramuscularly with a single inoculation of $0.01 \mathrm{~g}$ drug in $0.05 \mathrm{ml}$ distilled water. The quantity of drug eaten could not be calculated because different fish ate different amounts. A fresh preparation was made up every other feeding because fish rejected old preparations.

Histological sections were stained with Harris' hematoxylin and eosin; other stains mentioned in the text followed the methods described in manuals by Luna (1968) and Wells (1966).

\section{RESULTS}

\section{Prevalence, specificity, and known distribution of $E$. funduli}

We observed $E$. funduli first in 1969 when a few individuals of Fundulus grandis from Halstead Bayou, Ocean Springs, Mississippi, had infections. Based on occasional observations, the prevalence of infection remained low until March 1975 when it reached about 10\%. During a period from 1977 through 1979 , however, all of more than 500 fish examined had infections regardless of age, sex, or season collected. These fish came from a variety of habitats extending from Bay St. Louis, Mississippi, to Bayou La Batre, Alabama.

Species of killifishes other than $F$. grandis also harbored E. funduli. Two samples (totaling 75 fish) of the longnose killifish, F. similis (Baird and Girard) caught off Ocean Springs beaches revealed infections in all the mature fish, in some medium-sized fish, and in a few small fish. No infected fish of any size occurred in several collections from beaches and ponds of Horn Island, an island about 10 $\mathrm{km}$ south of Ocean Springs that separates brackish Mississippi Sound from the consistently higher salinity water of the Gulf of Mexico. A few individuals of the bayou killifish, F. pulvereus (Evermann), from Ocean Springs hosted the coccidium as did the mummichog, F. heteroclitus (Linnaeus), from the vicinity of Gloucester Point, Virginia.

\section{Sites of infection}

Duszynski et al. (1979) described the sporulated oocyst of E. funduli in detail. The oocysts occurred primarily in the liver and pancreas of the hosts. Livers of naturally infected fish usually had isolated oocysts and aggregations of several thousand oocysts separated from liver parenchyma by a thin layer of noncollagenous host tissue (Figs. 1-3). In

Figures 1-7. Oocysts of Eimeria funduli from the Gulf killifish or grass shrimp and a possible stage of the coccidium from the shrimp. 1. Liver and pancreas of Fundulus grandis showing moderately heavy infection; note that oocysts occur individually or in aggregations. H \& E. $\times 195.2$. Enlargement of infected pancreas and adjacent liver from Figure 1; few acinar cells of pancreas remain; note that all oocysts are sporulated. H \& E. $\times 390$. 3. Nonstained fresh oocyst from fish liver, fish probably more than $1 \mathrm{yr}$ old. $\times 1,890$. 4. Unidentified cells from hepatopancreas of infective grass shrimp, fresh squash. Nomarski optics. $\times 550$. 5. Same cells as in Figure 4 separated from adjacent host tissue. $\times 300$. 6. Sagittal section of grass shrimp midgut $4 \mathrm{hr}$ after being fed infected fish liver. H \& E. $\times 60.7$. Enlargement of Figure 6 showing oocysts and partially digested liver tissue. $\times 780$. 


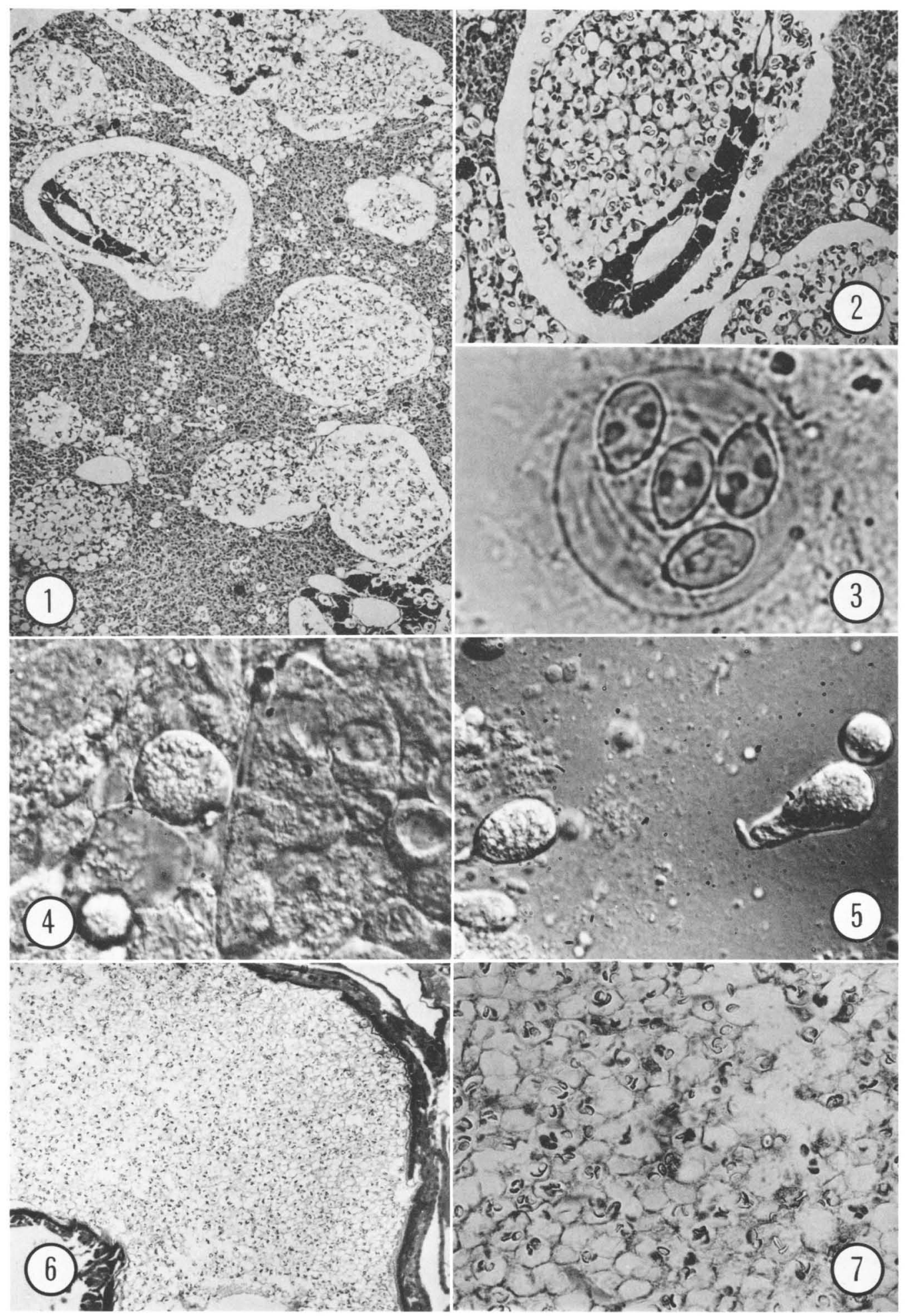


heavy infections, about $85 \%$ of the liver consisted of oocysts. Pancreatic tissue, located both within the liver proper and externally abutting the liver and intestine, also was replaced partially or totally by these aggregates; the organism infected cells both of the islets and acini. Individual fish harboring intense, natural infections often had single oocysts or small aggregations of them in fatty tissue lying in the vicinity of the mesentery and occasionally in the ovary. Large aggregations of oocysts also were seen on single occasions in epithelium of intestine and caudal peduncle.

\section{Cross transmission}

We experimentally infected $F$. similis with the same stock of shrimp used to infect $F$. grandis, and the parasite located in the same primary sites.

\section{Route of infection}

Laboratory-reared $F$. grandis, fed either cleaned, sporulated oocysts or heavily infected liver tissue, failed to acquire infections, even when periodically fed these oocysts for over a 6-mo period. When examining the state of oocysts during passage of infected liver tissue through the alimentary tract of the fish, we observed intact oocysts only during the first $8 \mathrm{hr}$ after feeding, and they were restricted to the anterior half of the small intestine. Neither oocysts nor their remnants could be found in the intestine 12 to $24 \mathrm{hr}$ postfeeding; nor could oocysts be found in feces or in filtered suspended matter from small dishes used to maintain individuals. Histological sections of liver, intestine, gall bladder, gonads, spleen, brain, and cystic duct of fish at 10,20 , and 30 days after feeding of oocysts exhibited no obvious stages of the parasite or abnormal conditions.
However, we caused moderate to heavy infections in killifish by feeding them grass shrimp from epizootic areas. Shrimp that had consumed infected liver $2 \mathrm{hr}$ prior to being fed to the killifish and shrimp not fed oocysts produced infections. The original intent for using two groups of shrimp was to test a possible priming action of the parasite by the shrimp. Grass shrimp from Alabama ponds in which killifish had no infections did not produce infections, even when given oocysts 2 or $24 \mathrm{hr}$ prior to being fed to the fish. When we state that fish became infected, it is implied that all individuals examined had infections, and that all individuals in a group simultaneously harbored the same stages; this applies to all experiments and includes histological observations as well as those of fresh smears.

No coccidian stage could be identified from shrimp. In squashes of fresh tissues of naturally infected shrimp, we consistently saw a large cell with a body of refractile material associated with the hepatopancreas. This cell of unknown function was usually spherical (Fig. 4) unless separated from tissue of the hepatopancreas. In the case of the latter, the cell could elongate or transform into a gobletlike shape (Fig. 5); it occurred in especially high concentrations in some individuals. Uninfective shrimp from Alabama did not contain them, nor could they be confirmed in serial sections of five grass shrimp, three of which had been fed oocysts. Large numbers of intact oocysts occurred in a shrimp's midgut $4 \mathrm{hr}$ after being fed infected liver (Figs. 6, 7), but the number decreased considerably by 12 $\mathrm{hr}$ and almost to none by $24 \mathrm{hr}$. Feces of liverfed shrimp contained only a few intact oocysts.

Grass shrimp collected from the epizootic habitats remained infective at least 15 days and probably much longer.

FigurEs 8-15. Developmental stages of Eimeria funduli in liver and pancreas of 6-mo-old Fundulus grandis. H \& E. 8. Early schizont within parasitophorous vacuole displacing nearly all hepatocyte cytoplasm. Day 5. $\times 1,470$. 9. Schizont in hepatocyte with developing merozoites; note compressed host nucleus (arrow). Day 10. $\times 1,470.10$. Schizonts in acinar cells of pancreas. Day 10. $\times 390.11$. Mature schizont in liver showing 13 merozoites surrounding refractile body in rosette fashion. Day $10 . \times 1,470$. 12. Early microgamont. Day 18. $\times 1,470$. 13. Macrogamonts; note granules in cytoplasm, inflammatory cells, and lack of parasitophorous vacuole. Day $18 . \times 780$. 14. Fertilized macrogametes; note foamy cytoplasm, extra space within parasitophorous vacuoles, and dense infiltration of inflammatory cells. Day $20 . \times 780.15$. Developing oocysts with granular cytoplasm (single arrow) and mature microgametes (double arrow). Day 25. $\times 780$. 


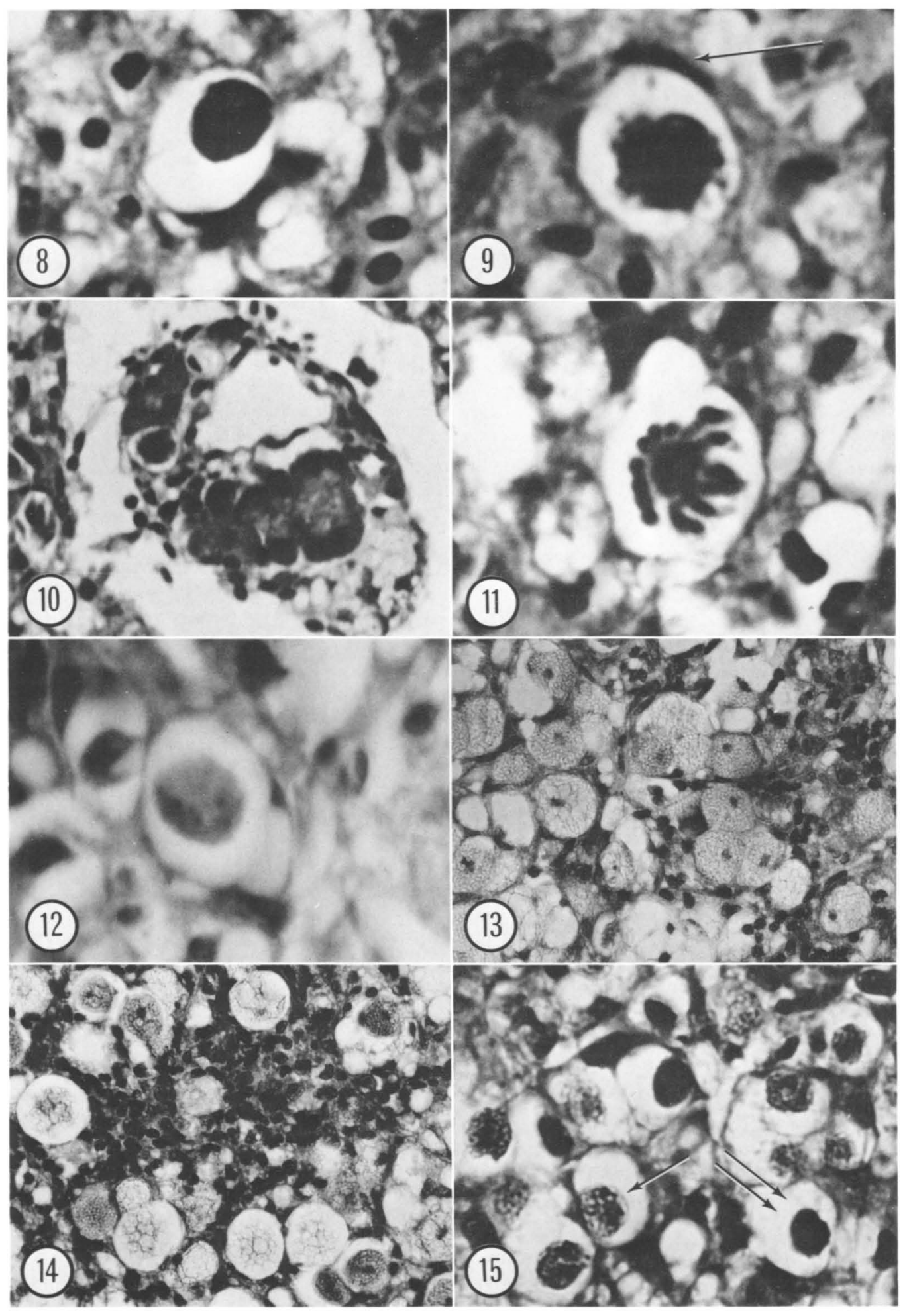




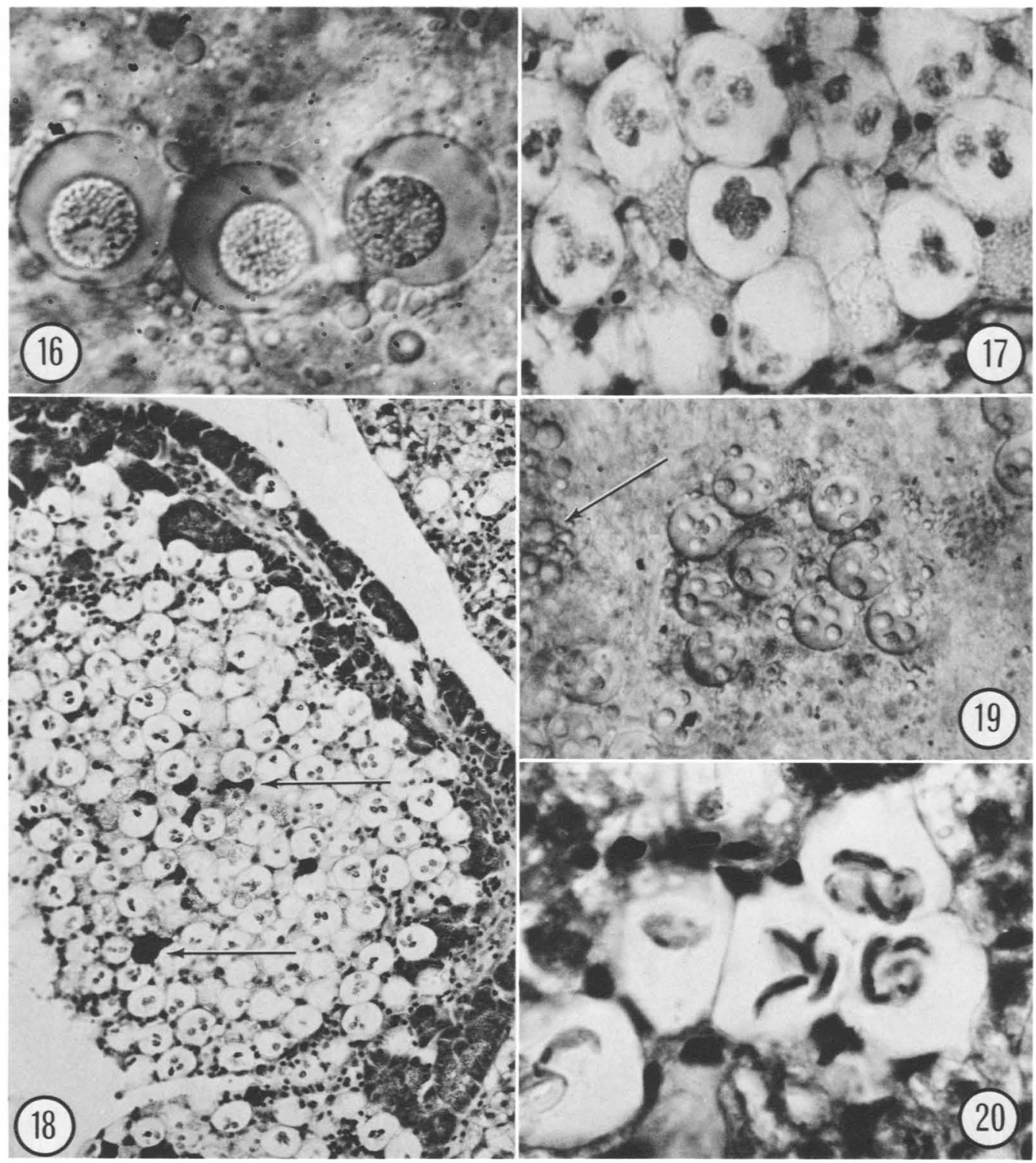

Figures 16-20. Developing oocysts of Eimeria funduli. 16. Squash preparation of fresh unstained material. Nomarski optics. Day 25. $\times 1,300$. 17. Sporogony showing formed and forming sporoblasts. Day 30 . H \& E. $\times 1,000$. 18. Oocysts with sporoblasts in pancreas; note "melanin" among aggregates (arrows). Day 30. H \& E. $\times 390$. 19. Squash preparation of liver. Nomarski optics. Note adjacent nonrelated lipid accumulation (arrow). Day $30 . \times 500.20$. Sporulated oocysts in liver; note compressed oocyst walls. Day 60. H \& E. $\times 1,470$.

\section{Endogenous development}

Histological sections of the fish's intestine, gall bladder, cystic duct, and common bile duct at days 10,20, and 30 with periodic feeding of infective shrimp exhibited no sign of infection. Even though initial invasion by the parasite was not observed, hepatocytes and pancreatic cells contained a young schizont at day 5 , but not at day 2 . These spherical to elliptical bodies, were 5 to 9 (avg. 7.3) $\mu \mathrm{m}$ across (Fig. 8), occupied a parasitophorous vacuole which was 8 to 12 (avg. 11.1) $\mu \mathrm{m}$ in 
diameter, and lay within the host cytoplasm. These and later stages described below are based on infections in 6-mo-old fish maintained at about $24 \mathrm{C}$.

Probable first-generation merozoites developed by day 10 (Figs. 9-11). Sections through 50 schizonts had 13 to 20 merozoites, 6 by 1 $\mu \mathrm{m}$, surrounding a refractile body (Fig. 11).

Between days 15 and 20, sexual stages became differentiated. Early microgamonts were subspherical, multinucleated bodies 6 to 7 (avg. 6.4) $\mu \mathrm{m}$ across within a 13- to $14-\mu \mathrm{m}$ (avg. 13.3) diameter, parasitophorous vacuole (Fig. 12). These microgamonts were basophilic when stained with $\mathrm{H} \& \mathrm{E}$, whereas the early macrogamont, also spherical to subspherical, typically occupied the entire vacuole and had a near centric nucleus surrounded by refractile granules (Fig. 13). These granules stained positively with PAS, a reaction destroyed by digestion with saliva.

Fertilization apparently occurred between days 19 and 26 as indicated by a foamy consistency of the zygote within the vacuole (Fig. 14). After fertilization, the cytoplasm condensed, became granular, and acquired an eccentric position in the vacuole (Figs. 15, 16). Nuclear division began between days 25 and 30 producing four sporoblasts (Figs. 17-19). By day 35, sporoblasts developed sporopodia and PAS-positive granules no longer remained. Sporozoites did not develop until about day 60 (Fig. 20).

\section{Susceptibility and variability in development}

Laboratory-reared $F$. grandis ranging in age from 3 mo to 3 yr all acquired infections when fed grass shrimp from Halstead Bayou, suggesting that fish of all ages are susceptible. The developmental period in various-aged fish, however, differed. Oocysts with four distinct sporoblasts developed in 4-mo-old fish by days 25 to 30 , in 6 -mo-old fish by days 30 to 35 , in 1-yr-old fish by days 35 to 40 , and in 3 -yr-old fish by days 60 to 65 . Merozoites in 6-mo-old fish had all developed by day 10 , whereas in 1-yr-old fish few merozoites developed at day 10, but many had developed by days 13 and 15 . Furthermore, the infection in killifish fed infective shrimp for 5 days, then transferred to a 7 to $10 \mathrm{C}$ aquarium ceased developing in the cold water. When examined 8, 12, and 30 days after transfer back to $24 \mathrm{C}$ aquaria (made at day 19 postfeeding), the fish exhibited no sign of infection, but had a decreased fat content.

Experimental infections of presumed uninfected $F$. similis collected from Horn Island exhibited similar variable periods of development. Appearance of sporoblasts in fish which were 3.5 to $4.0 \mathrm{~cm}$ long took 27 to 29 days and that in fish 6.0 to $7.5 \mathrm{~cm}$ long took about 33 days.

The quantity of tissue from grass shrimp that we fed to killifish had no appreciable effect on the ultimate intensity or developmental time of the parasite. The relative abundance of oocysts was similar in livers of fish fed pieces of shrimp equal to 1,5 , or $10 \%$ of their body weight within a single day's period. All these 13-mo-old fish developed moderately heavy infections, with sporoblasts forming at about day 40 .

Once oocysts developed in the liver of a fish, additional schizogonic and gamogonic stages did not establish in that same individual even though we fed infective shrimp to such fish daily for 30 days.

\section{Gross pathology and pathogenesis}

Heavily infected fish exhibited pale white to black lesions that were densely scattered throughout the liver parenchyma and were evident especially at the periphery of the normal reddish-brown liver. Histological sections through the lesions showed them to be large aggregations of oocysts replacing up to $85 \%$ of the liver and pancreatic tissue (Figs. $1,2,18)$. Many aggregations were elliptical in shape, 217 to $380 \mu \mathrm{m}$ long by 155 to $266 \mu \mathrm{m}$ wide, and others were irregularly shaped, being more than $1 \mathrm{~mm}$ long. Host response to large aggregates and single oocysts was minimal, whereas fibrotic capsules occasionally surrounded small aggregates and their associated dark pigment. Most capsules surrounded clumps of 20 to 40 oocysts, but others contained from four to a few hundred. Occasionally, single oocysts were encircled by collagen within an encapsulated aggregate, but collagen usually was confined to an entire group. In the ovary, most infections consisted of single oocysts without encapsulation or associated pigmentation. In fatty tissue about the intestine, small, usually nonencapsulated aggregates had enough pigment to be seen without magnification. 
TABLE I. Staining reactions of liver and pancreas of Fundulus grandis at various days after being infected with Eimeria funduli.

\begin{tabular}{|c|c|c|c|c|c|c|}
\hline \multirow[b]{2}{*}{ Stain } & \multicolumn{4}{|c|}{ Day postfeeding } & \multicolumn{2}{|c|}{ Stain } \\
\hline & 10 & 18 & 20 & 30 & Positive reaction & Site \\
\hline Masson's trichrome method & - & + & + & + & Collagen & Surrounding aggregates \\
\hline Van Gieson's method & - & + & + & + & Collagen & Surrounding aggregates \\
\hline $\begin{array}{l}\text { McManus' method for glycogen } \\
\text { (PAS) with saliva digestion }\end{array}$ & - & + & + & - & Polysaccharide & $\begin{array}{l}\text { Within encapsulation } \\
\text { and gamonts }\end{array}$ \\
\hline $\begin{array}{l}\text { Ziehl-Neelsen method } \\
\text { for acid-fast bacteria }\end{array}$ & - & + & - & - & Acid-fast debris & Within encapsulation \\
\hline AFIP method for lipofuscin & - & + & + & - & Lipofuscin & Within encapsulation \\
\hline Nile blue method & - & + & + & +0 & $+=$ lipofuscin $; 0=$ "melanin" & Within encapsulation \\
\hline $\begin{array}{l}\text { Schmorl's method } \\
\text { for reducing substances }\end{array}$ & - & + & + & + & Argentaffin granules & Within encapsulation \\
\hline Fontana-Masson silver method & & & & + & $\begin{array}{l}\text { "Melanin" and argentaffin } \\
\text { granules }\end{array}$ & Within encapsulation \\
\hline $\begin{array}{l}\text { Perl's iron method } \\
\text { for ferric iron }\end{array}$ & - & - & - & - & Lacking & \\
\hline $\begin{array}{l}\text { Lillie's method for } \\
\text { ferric and ferrous iron }\end{array}$ & - & - & - & - & Lacking & \\
\hline
\end{tabular}

The first histological sign of a host's response became obvious at about day 10 when a few inflammatory cells infiltrated the liver in an apparent random manner. About day 18, many cells, mainly lymphocytes, mononuclear macrophages, and eosinophils, accumulated around some gamonts (Fig. 21). Simultaneously, an abundance of relatively large fibroblasts layed down collagen around small aggregates of gamonts (Figs. 22, 23). By day 20 , the inflammatory response intensified, but was limited to relatively few foci typically near blood vessels. Concurrently, considerable yellow to brown pigmentation occurred within fibrotic capsules, which, by this time, were multilayered and surrounded by inflammatory cells (Figs. 24, 25). The pigment darkened with time (Figs. 26-28). By day 30 when the oocyst wall was fully developed, inflammatory infiltrates diminished or disappeared. Table I summarizes the histochemical reactions we assayed during the study. Collagen surrounded oocysts by day 18 . The encapsulated material contained no iron (thus, no he- mosiderin), but the enclosed yellowish pigment at day 18 was positive for lipofuscin, argentaffin granules, and polysaccharide. By day 18 , but not 20 or 30 , the debris showed positive staining for acid-fast material. By day 30 , the response for lipofuscin was accompanied by one for "melanins." The dark pigment material at day 30 stained positively with the Fontana-Masson silver method, but could not be removed with potassium permanganate solution as expected for most melanins.

\section{Control of disease}

We gave large doses of Monensin to infected fish in a preliminary study to test the potential of chemical treatment of infections. Specimens of $F$. grandis that had natural and experimental infections with sporulated oocysts and were either injected with the drug intramuscularly or fed it had 50 to $70 \%$ fewer oocysts than control fish when compared 10 to $\mathbf{1 5}$ days after administration of the drug. In treated fish that were killed 7 to 10 days after

Figures 21-28. Pathological responses to Eimeria funduli infection. 21. Infiltration of inflammatory cells near aggregates of gamonts, showing typical reaction near blood vessel; note proteinaceous material in central vein. Day 18. H \& E. $\times 390$. 22. Encapsulated gamonts in pancreas; note necrotic centers and “ceroid" pigment. Day 18. H \& E. $\times 390$. 23. Encapsulation of small aggregate of gamonts in liver. Day 18. H \& E. $\times 780$. 24. Multilayered capsule. Day 20 . H \& E. $\times 1,000$. 25. Inflammation around capsules. Day 20. H \& E. $\times 390$. 26. Encapsulated aggregate of gamonts showing fibrotic capsules and associated lipofuscin pigment. Day 25. H \& E. $\times 1,470$. 27. Fresh squash showing fibrotic multilayered capsule about small aggregate of unsporulated oocysts and lipofuscin pigment. Day $35 . \times 780.28$. Fresh squash of advanced state of encapsulation; note blackish colored pigment. Day 50: $\times 780$. 


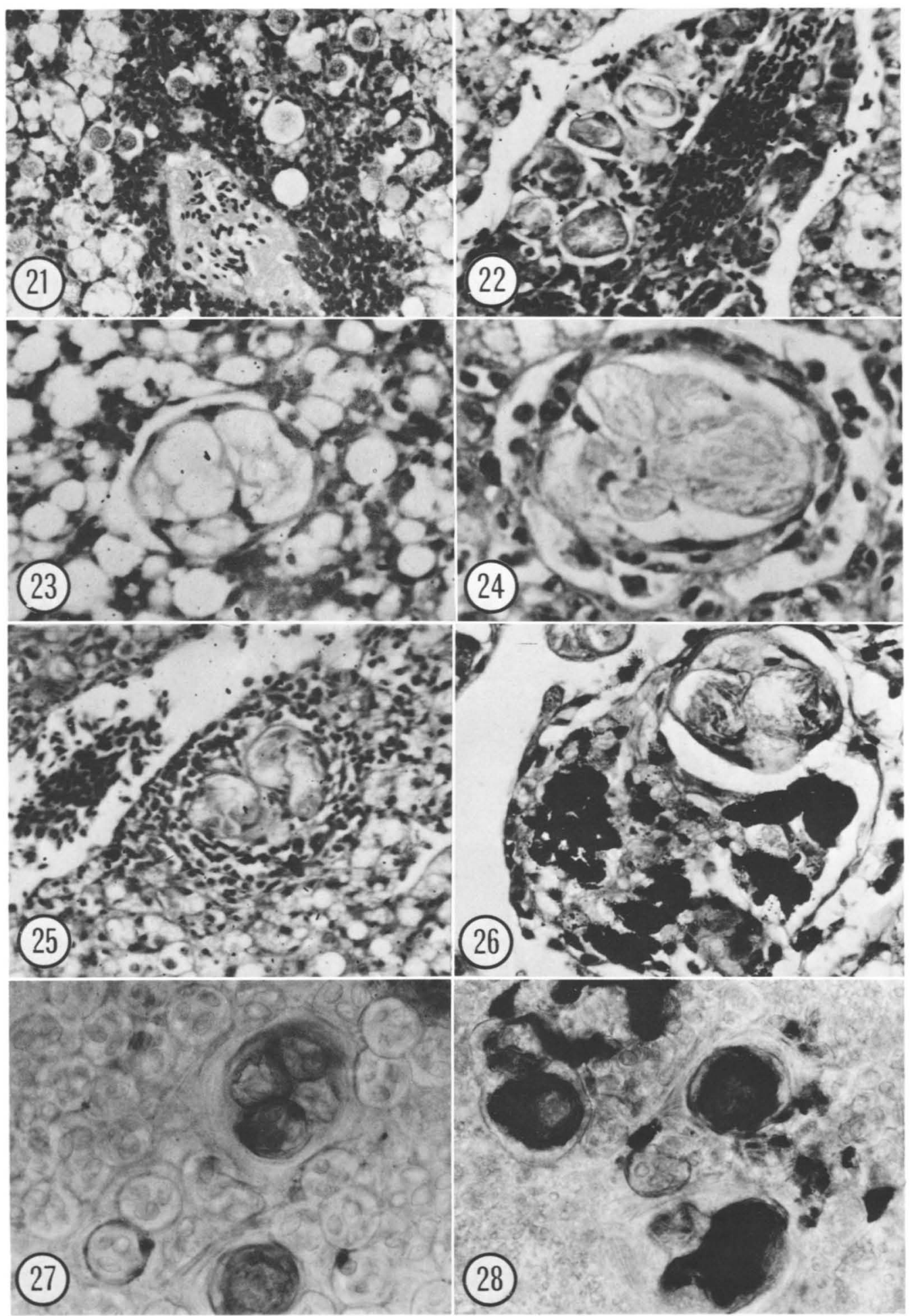


administering the drug, encapsulation and production of pigment increased dramatically when compared to nontreated controls. In the injected fish, crystalline deposits, presumably drug residue, occurred near the injection site at days 7 to 10 , and all the injected fish died by day 20 . In contrast, fish fed orally lived the entire 20 days of the experiment.

Ten naturally infected and 10 experimentally infected fish maintained exclusively on TetraMin fish food for over 3 mo completely lost their infections, whereas others fed on fish and trout chow remained infected. The livers of fish that lost the infection decreased to about one-third their original size. Although they contained some lipid deposition, those livers had a deep red color similar to livers of wild fish in contrast to the cream-colored livers of infected counterparts.

\section{DISCUSSION}

An entire $F$. grandis stock in an area may be infected by $E$. funduli. Because the organism apparently was unknown before 1969, prevalence before that time cannot be established. Since then, the prevalence of infected $F$. grandis gradually has increased until every fish examined from Mississippi during the last $3 \mathrm{yr}$ had the infection. In contrast, all $F$. similis from Horn Island, were uninfected; this is not true of those from Ocean Springs. Moreover, we predict that careful examination of estuarine killifish from the northern Gulf of Mexico well up the Atlantic coast will yield infected disjunct stocks during specific years. Fantham and Porter (1948) reported an unidentified species of Eimeria in $F$. heteroclitus from Halifax, Nova Scotia; this species may be E. funduli, which we have observed in fishes from Virginia.

Eimerians typically infect a single species of host. In fact, some species thought to infect more than one host species actually represent more than one taxon (e.g., Stockdale et al., 1979). Eimeria funduli is based on syntypes from $F$. grandis, but shrimp with infective stages for that host also infected $F$. similis under experimental conditions. We also found similar, natural infections in liver and pancreas of $F$. similis, $F$. pulvereus, and $F$. heteroclitus and oocysts, with sporocysts indistinguishable from those of $E$. funduli, in the skin and intestine of $F$. grandis. The latter infec- tions appeared superficially as myxosporidan infections and may have been ignored in the past. In any event, the distribution of $E$. funduli suggests that a wide range of killifish may serve as normal hosts and that the parasite has unusual aspects to its life cycle.

Most piscine eimerians infect the intestine or pyloric ceca, but a few have been reported in the liver, spleen, kidney, swim bladder, and other visceral organs (Pellérdy, 1974). Little more than descriptive data on sporulated oocysts exist for extraintestinal species. Nevertheless, all infections of Eimeria spp. from fish and other hosts have been assumed to be transmitted directly by the oocyst without a second host. For oocysts of nonintestinal piscine species to exit from a host, the fish must be eaten or die and decompose. Fiebiger (1913, fide Pellérdy, 1974: 77), however, considered the possibility that sporozoites of $E$. gadi Fiebiger 1913 could penetrate the cardiovascular system from the air bladder and thus be available to a blood-sucking ectoparasite which in turn could transfer them to another fish. However, a life cycle similar to the one we found seems more probable.

Experimental transmission of E. funduli involves a grass shrimp. We directed considerable, unsuccessful effort toward attempting to infect $F$. grandis directly with sporulated oocysts. Whether additional hosts can serve in this capacity in the natural environment is unknown. Five laboratory-reared fish were fed with juveniles of the blue crab, Callinectes sapidus Rathbun, from an enzootic area, but no infection was observed in the fish. Other crustaceans, however, may transmit the parasite because all-sized individuals of $F$. grandis had infections. This observation suggests that small fish may become infected from a different, small crustacean, perhaps a very young Palaemonetes pugio, or pieces of grass shrimp from those being eaten by other fish. The fact that relatively old, but not young, $F$. similis were infected in an area (front beach of Ocean Springs) where young, infected $F$. grandis occurred suggests that small $F$. similis, most common in Mississippi along the barrier islands, 1) had a different diet than small $F$. grandis, 2) were recently recruited into the inshore stock, or 3) were more resistant to infection than their adult counterparts. Because 3-cm-long F. similis are easily infected experimentally, a different 
diet appears the most acceptable view, although killifishes naturally feed on grass shrimp as well as a variety of other items (Harrington and Harrington, 1961; Subrahmanyam and Drake, 1975).

In some species of microsporidans, spores become more infective to the proper host after they pass through or remain in certain nonsusceptible "hosts" (e.g., Scarborough and Weidner, 1979). The shrimp does more than "prime" the organism, because shrimp from a nonenzootic area that were fed oocysts were not infective to killifish after either 2 or $24 \mathrm{hr}$. The infective stage in the hepatopancreas or elsewhere in the shrimp, whether it is a sporozoite, modified sporozoite, or asexually produced progeny of a sporozoite, apparently needs more than $24 \mathrm{hr}$ for development. On the other hand, shrimp from enzootic areas maintained the stage for at least 15 days, but not indefinitely.

Once the organism from the crustacean enters the fish, it probably reaches the liver via the blood stream. Infections in killifish do not occur in the bile duct or intestine, and sporozoites of E. stiedai (Lindemann 1865) apparently invade through the blood (Owen, 1970). This route also would explain the occasional extrahepatic sites we noted, possibly exclusive to especially susceptible individuals.

Eimerians that develop oocysts in extraintestinal sites are an enigma, and, to date, the life cycles of these unusual species are unknown. On the other hand, development of $E$. stiedai from liver of rabbits has been well established and it differs considerably from that of E. funduli in killifish. Eimeria stiedai parasitizes epithelium of the bile duct, whereas E. funduli infects hepatocytes and pancreatic cells. In $E$. stiedai, the first generation merozoites form Type A and Type B schizonts, which, each in turn, ultimately produces four more asexual generations predetermined as either macro- or microgamonts. Not all species have such early predetermined replication. We have no evidence that Type A and B schizonts exist in E. funduli; however, we did not delineate different generations in our material.

The general formation of the wall of the oocyst appeared similar to that in some other studied eimerians. Other studies have determined that polysaccharide granules, forming the wall and losing their PAS-staining reaction when digested with saliva, as found in $E$. funduli, consist of amylopectin rather than glycogen (Ryley, 1973: 149). Oocyst walls of different species vary. That of $E$. funduli (examined with polarized light at day 22 and 4 mo) does not have a birefringent layer as contained in some (e.g., Ryley, 1973: 153); however, E. funduli and most piscine eimerians have a thin wall.

A synchronous development resulted in over $99 \%$ production of sporoblasts during the same day for fish of the same age in a given test. The ranges in developmental times noted in fish of the same age might be caused by at least three factors-temperature differences, host influences, and period of feeding. We fed infective shrimp to killifish for one day in some experiments and for longer periods in others.

Dose of administered oocysts, at least at certain levels, apparently does not influence intensity of infections in fish. Identical intensities occurred whether shrimp in quantities of 1,5 , or $10 \%$ of the fish's weight were eaten. The intensity of infection in all these cases reached between 50 and $85 \%$ of the liver. Perhaps $1 \%$ was a large enough dose to surpass a threshold value, and a smaller dose would have resulted in fewer oocysts. The high level was common for infections in the natural environment in Mississippi, but in Bayou La Batre, Alabama, livers of all $13,2-$ to $2 \frac{1}{2}-\mathrm{yr}-$ old $F$. grandis examined had only 5 to $10 \%$ of the liver replaced by oocysts. Those infections primarily involved pancreatic cells. Whether dose, host resistance, or diet influenced infections with low intensity was not established.

Sporogony and schizogony in E. funduli and $E$. similis occurred more rapidly in young than in old fish and was influenced by temperature. Low temperature irreversibly terminated schizogony in experimentally infected fish, but did not eliminate established oocysts. In the natural environment, sporogony apparently can be arrested. Whereas all wild fish of all sizes had infections, oocysts occasionally were unsporulated. Because old fish presumably had been infected longer than 60 days, we assume some factors such as temperature and nutrition regulate sporulation. With mammalian eimerians, older hosts often exhibit more susceptibility to coccidio- 
sis than their younger counterparts (Long, 1973: 260). However, schizogony and gamogony usually are constant in those hosts. Rose (1973: 304) mentioned cases in which the prepatent period for mammalian eimerians was extended in hosts treated with a corticosteroid (Long and Rose, 1970). Perhaps variable developmental periods relative to host age, temperature, immunity, and other factors is commonplace in eimerians infecting cold-blooded vertebrates.

We did not investigate immunological responses to $E$. funduli, but we believe that premunition exists. Fish with sporulated oocysts in their liver did not exhibit additional gamogony or sporogony even though fed infective grass shrimp continually for periods as long as 30 days.

Although numerical data are not available, we have noted an obvious decline in $F$. grandis in Ocean Springs bayous during the past few years when prevalence and intensity of $E$. funduli infections in $F$. grandis have been correspondingly high. Also, two local people who have collected this bait fish for about 15 yr from the same locality at Halstead Bayou commented to us that their harvests have been reduced dramatically during the last 3 yr and are composed of smaller fish. Environmental fluctuations or overfishing for bait could cause the decline in abundance and individual size; however, the cause could be related to $E$. funduli. Because up to $85 \%$ of the hepatocytes and pancreatic tissue can be destroyed by the parasite, heavily infected hosts probably have difficulty surviving when they undergo excessive environmental and nutritional stress normally counterbalanced by functions of those organs.

In light, natural infections, the host encapsulated all or most of the oocysts. In heavy, experimental infections, however, the host response appeared inadequate to deal with all the oocysts present. Similar to that response noted for other eimerians (Long, 1973: 268), a progressive increase in cellular response began while first generation merozoites developed. The number of cells steadily increased during schizogony and gamogony. Once oocysts began to form, that number declined, leaving a few concentrated foci, primarily located near blood vessels. Gamonts encapsulated by collagen comprised a small proportion of those present in experimental infections. By contrast, in fish treated with Monensin, just as in those with light, natural infections, nearly all parasites were encapsulated and destroyed.

During the progression of experimental infections of $E$. funduli, pigments associated with that development changed from yellow to brown to black; this probably represents a transgression of oxidized lipid residues unified as lipofuscin granules (see Ghadially, 1977 , for review). The acid-fast material, considered by some as a lipofuscin-type ceroid (Roberts, 1975: 422), has a yellowish appearance at day 18 . By day 20 , it appeared brownish and stained as lipofuscin by several methods (Table I). By day 30, it nearly turned black and stained as melanin using Nile blue and Fontana-Masson's methods (Table I), although it could not be removed by potassium permanganate as expected of "melanin" (Luna, 1968). We recognize that "melanin" differs both among different animal groups and among different tissues in the same species. Additionally, melano-macrophage centers of fishes typically stain positive for ferric iron in the spleen, suggesting the degradation of red blood cells. These centers seldom exhibit a positive reaction in the kidney or liver of either healthy or diseased individuals (Agius, 1979). Macrophages within and around capsules of $E$. funduli did not contain ferric or ferrous iron.

Because laboratory-reared fish often have higher than normal triglyceride levels with correspondingly higher lipid residues, we might expect more pigmentation in our laboratory-reared infected fish than in those naturally caught (Roberts, 1975: 422). Actually, even though the livers in the laboratoryreared specimens had considerably more fat deposition than wild fish, the livers in the naturally infected fish had more pigmentation. Fatty livers, also periodically common in natural fish populations and resulting from a variety of causes (Overstreet, 1974), did not seem to influence the progression or severeness of the coccidial infection.

Even though infections did not kill our experimental hosts, the potential for harm to fish in the natural environment or in aquaculture facilities is great, especially during periods of stress. Culture of killifish as a bait fishery takes place primarily in ponds subject to some stresses of the environment. Eimerians other 
than E. funduli already have been implicated in considerable losses of pond-reared fish, even though few are well documented. For example, in 4- to 6-wk-old fry infected with E. sinensis Chen 1956, mortality sometimes reached 60 to $70 \%$ of the stock (Molnár, 1976). In that case, however, a gill ectoparasite may have provided an additional stress.

We intentionally treated infected killifish with excessive quantities of Monensin to determine possible benefits and side effects. Of the fish given intramuscular injections, none survived 20 days. However, using the drug orally did not kill the fish, was easy to administer, and was highly effective. Additional studies using lower concentrations of the drug should prove rewarding, and we assume infections can be completely cleared with proper doses after some period longer than 20 days.

Feeding infected fish TetraMin probably would be less economical than treating them with Monensin, but understanding the reason infected fish fed TetraMin lost their infections has important implications. According to G. Ritter of Tetra Werke (pers. comm.) the formula did not include medication or synthetic antioxidants. Perhaps the presence or absence of specific dietary needs was responsible. Crude protein content was 45 to $46 \%$. If the diet, such as protein content and vitamin requirements, influences susceptibility or host response, then an alteration in a stock's diet can explain observed fluctuations of prevalence of infection and abundance of fish. TetraMin affected the parasite only after oocysts formed. When we used it to feed fish, as we did commonly at the onset of our study, infections were not prevented.

\section{ACKNOWLEDGMENTS}

This study was conducted in cooperation with U.S. Department of Commerce, NOAA, National Marine Fisheries Service, under PL 88-309 Project No. 2-325-R. We thank the following people for their help: Adrian R. Lawler and Steven L. Shepard of GCRL provided laboratory-reared killifish; William C. Trimble of Claude Peteet Mariculture Center, Gulf Shores, Alabama, provided pond-reared fish; from GCRL, Joan D. Durfee helped section tissue, Ronnie G. Palmer helped examine fish, John T. Ogle and Donald W. Bump helped maintain fish and aquaria, and Rena A. Krol and Lucia O'Toole typed the manuscript; Robert R. Miller of the University of Michigan identified $F$. pulvereus; Thomas K. Jeffers of Eli Lilly and Co. provided the Monensin; and Donald W. Duszynski of University of New Mexico provided critical comments on the manuscript.

\section{LITERATURE CITED}

Agius, C. 1979. The role of melano-macrophage centres in iron storage in normal and diseased fish. J Fish Dis 2: 337-343.

Duszynski, D. W., M. A. Solangi, and R. M. Overstreet. 1979. A new and unusual eimerian (Protozoa: Eimeriidae) from the liver of the Gulf killifish, Fundulus grandis. J Wildl Dis 15: 543-552.

Fantham, H. B., AND A. Porter. 1948. The parasitic fauna of vertebrates in certain Canadian fresh waters, with some remarks on their ecology, structure and importance. Proc Zool Soc London 117: 609-649.

GHADIALLY, F. N. 1977. Ultrastructural pathology of the cell. Butterworth \& Co. Ltd., London, $543 \mathrm{p}$.

Harrington, R. W., JR., AND E. S. Harrington. 1961. Food selection among fishes invading a high subtropical salt marsh: From onset of flooding through the progress of a mosquito brood. Ecology 42: 646-666.

LONG, P. L. 1973. Pathology and pathogenicity of coccidial infections. In D. M. Hammond and P. L. Long (eds.), The coccidia. University Park Press, Baltimore, Maryland, p. 254-294.

$\longrightarrow$, AND M. E. Rose. 1970. Extended schizogony of Eimeria mivati in betamethasone-treated chickens. Parasitology 60: 147-155.

LUNA, L. G. (ED.). 1968. Manual of histologic staining methods of the Armed Forces Institute of Pathology. 3rd ed. McGraw-Hill Book Company, New York, New York, 258 p.

McIllwain, T. D. 1977. Bait fish rearing. Mississippi Marine Resources Council Project No. GR-76-005, Gulf Coast Research Laboratory, Ocean Springs, Mississippi, $14 \mathrm{p}$.

MolNáR, K. 1976. Histological study of coccidiosis caused in the silver carp and the bighead by Eimeria sinensis Chen, 1956. Acta Vet Acad Sci Hung 26: 303-312.

Overstreet, R. M. 1974. An estuarine low-temperature fish-fill in Mississippi, with remarks on restricted necropsies. Gulf Res Rep 4: 328350 .

OWen, D. 1970. Life cycle of Eimeria stiedae. Nature 227: 304.

PelléRdy, L. P. 1974. Coccidia and coccidiosis. 2nd ed. Akademiai Nyomda, Budapest, Hungary, $959 \mathrm{p}$.

RoBERTS, R. J. 1975. Melanin-containing cells of teleost fish and their relation to disease. In W. R. Ribelin and G. Migaki (eds.), The pathology 
of fishes. The University of Wisconsin Press, Madison, Wisconsin, p. 399-428.

Rose, M. E. 1973. Immunity. In D. M. Hammond and P. L. Long (eds.), The coccidia. University Park Press, Baltimore, Maryland, p. 295-341.

RYLEY, J. F. 1973. Cytochemistry, physiology, and biochemistry. In D. M. Hammond and P. L. Long (eds.), The coccidia. University Park Press, Baltimore, Maryland, p. 145-181.

Scarborough, A., AND E. Weidner. 1979. Field and laboratory studies of Glugea hertwigi (Microsporida) in the rainbow smelt Osmerus mordax. Biol Bull 15 7: 334-343.

Stockdale, P. H. G., G. B. Tiffin, G. Kozub, AND B. CHовотAR. 1979. Eimeria contorta Haber- korn, 1971: A valid species of rodent coccidium. Can J Zool 57: 264-270.

Subrahmanyam, C. B., AND S. H. DRAKe. 1975. Studies on the animal communities in two north Florida salt marshes. Bull Mar Sci 25: $445-465$.

Tatum, W. M., W. C. Trimble, and R. F. Helton, JR. In press. Production of Gulf killifish in brackish water ponds. Proc Annu Conf Southeast Assoc Game Fish Comm 33.

WELls, G. G. 1966. Manual of histologic technics. University of Tennessee Institute of Pathology, Center for the Health Sciences, 800 Madison Ave., Memphis, TN 38163. 256 p. 